\title{
In conversation with Yousif Naser
}

\author{
Shakila Maan*
}

*Correspondence: shakila@shakilamaan.com

Shakila Maan has produced a short film to accompany Yousif Naser's paintings that are appearing in the journal. The short film, "In conversation with Yousif Naser" presents an intimate vignette into this extraordinary painter's life. Yousif has been living in London since the early 1980s and has silently contributed to the development of art in the UK and across Europe. He recently returned to Iraq for the first time and found a country devastated and unrecognisable.

"In conversation with Yousif Naser" also explores the artist's work, illustrating the tireless nature of his approach to his art, which is rapid and in a state of evolution; the essence always being a voice of dissent.

Yousif's unique art remains at the forefront of painting on the world stage, breaking new ground with works such as Black Rain, Exercise in Desperation, Letters to Nobody, Dark Walls, Ten Seasons and Seasons of Mud.

Please click on the image below to access the video:

(C) Copyright: Femminist Dissent/Shakila Maan, 2016

All rights reserved.

Music: 'Drone in D' by Kevin MacLeod licensed under the terms of the Creative Commons Attribution 4.0 license.

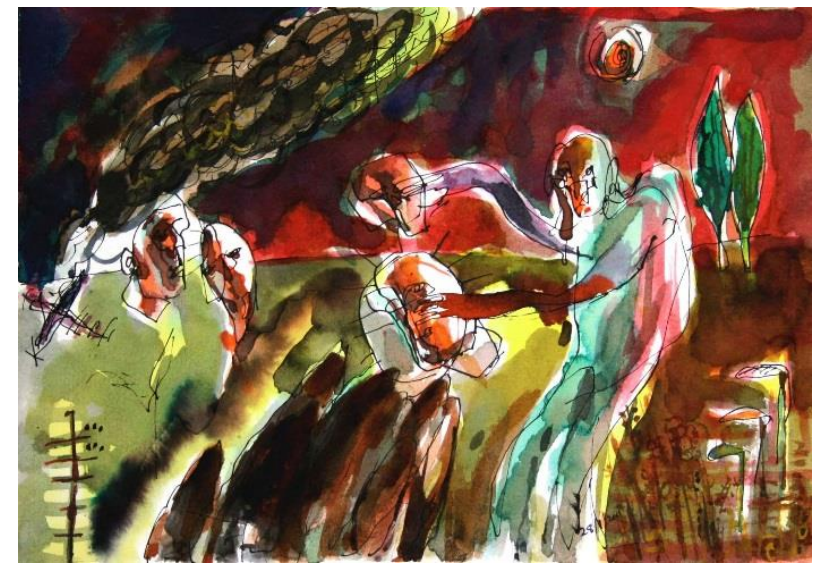

Shakila Maan is a film maker and writer. She is part of Southall Black Sisters and was a member of Women Against Fundamentalism.

To cite this article:

Maan, S. (2016). In Conversation with Yousif Naser. Feminist Dissent, (1), pp. 131. Retrieved from:

http://journals.warwick.ac.uk/index.php/feministdissent/article/view/20 